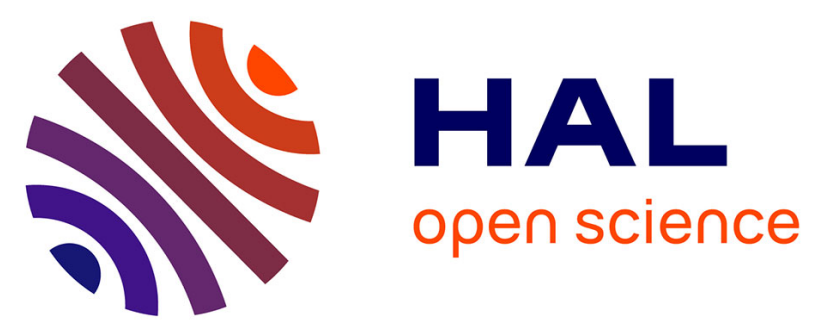

\title{
Room-Temperature Synthesis of BPH Zeolite Nanosheets Free of Organic Template with Enhanced Stability for Gas Separations
}

Edwin Clatworthy, Maxime Debost, Nicolas Barrier, Stéphanie Gascoin, Philippe Boullay, Aurélie Vicente, Jean-Pierre Gilson, Jean-Pierre Dath, Nikolai Nesterenko, Svetlana Mintova

\section{To cite this version:}

Edwin Clatworthy, Maxime Debost, Nicolas Barrier, Stéphanie Gascoin, Philippe Boullay, et al.. Room-Temperature Synthesis of BPH Zeolite Nanosheets Free of Organic Template with Enhanced Stability for Gas Separations. ACS Applied Nano Materials, 2021, 4 (1), pp.24-28. 10.1021/acsanm.0c02925 . hal-03143339

\section{HAL Id: hal-03143339 \\ https://hal.science/hal-03143339}

Submitted on 16 Feb 2021

HAL is a multi-disciplinary open access archive for the deposit and dissemination of scientific research documents, whether they are published or not. The documents may come from teaching and research institutions in France or abroad, or from public or private research centers.
L'archive ouverte pluridisciplinaire HAL, est destinée au dépôt et à la diffusion de documents scientifiques de niveau recherche, publiés ou non, émanant des établissements d'enseignement et de recherche français ou étrangers, des laboratoires publics ou privés. 


\title{
Room-Temperature Synthesis of BPH Zeolite Nanosheets Free of Organic Template with Enhanced Stability for Gas Separations
}

\author{
Edwin B. Clatworthy, ${ }^{\dagger}$ Maxime Debost ${ }^{\dagger}$ Nicolas Barrier, ${ }^{\dagger}$ Stéphanie Gascoin,${ }^{\ddagger}$ Philippe Boullay, ${ }^{\ddagger}$ \\ Aurélie Vicente, ${ }^{\dagger}$ Jean-Pierre Gilson, ${ }^{\dagger}$ Jean-Pierre Dath, ${ }^{\|}$Nikolai Nesterenko, Svetlana Mintova ${ }^{\dagger *}$ \\ $\dagger$ Normandie Universite, ENSICAEN, UNICAEN, CNRS, Laboratoire Catalyse et Spectrochimie (LCS), 14050 Caen, \\ France
}
¥ Normandie Universite, ENSICAEN, UNICAEN, CNRS, Laboratoire de Cristallographie et Science des Matériaux (CRISMAT), 14050 Caen, France

$\|$ Total Research and Technology, Feluy, B-7181 Seneffe, Belgium

Supporting Information Placeholder

\begin{abstract}
BPH-type synthetic aluminosilicate zeolite (Linde Q) nanosheets are synthesized at room temperature without organic structure-directing agents (OSDAs). The BPH nanosheets (7 $\mathrm{nm}$ thick, $90 \mathrm{~nm}$ across, $\mathrm{Si} / \mathrm{Al}=1.3$ ) are formed in a colloidal suspension using a mixture of structure-directing cations $\left(\mathrm{Cs}^{+}, \mathrm{K}^{+}\right.$ and $\mathrm{Na}^{+}$). In situ XRD reveals the high stability of the $\mathrm{BPH}$ nanosheets up to $500{ }^{\circ} \mathrm{C}$ under vacuum $(0.021 \mathrm{mbar})$ due to the presence of $\mathrm{Cs}^{+}$. The high $\mathrm{CO}_{2}$ adsorption capacity $(3.78 \mathrm{mmol} / \mathrm{g}$ ) and stability of the BPH nanosheets open the door for the preparation of oriented thin films and membranes for gas separation applications.
\end{abstract}

Zeolites have been the subject of significant research for the last 70 years because of their applications in key petrochemical processes and consumer products. ${ }^{1}$ Such research includes the synthesis of zeolites with nanoscale dimensions to achieve higher surface area and improved diffusion properties, a high silica content to improve their thermal stability, and new structures. ${ }^{2-3}$ To achieve these outcomes organic structure-directing agents (OSDAs) are frequently employed, however, their use is undesirable because of their high cost and necessary post-synthetic removal resulting in increased energy-use, emissions $\left(\mathrm{NO}_{\mathrm{x}}, \mathrm{CO}_{\mathrm{x}}\right)$, and can reduce the zeolite crystallinity and provoke leaching of Al. While high-silica zeolites are necessary for high temperature processes, low-silica zeolites, which can offer a greater number of acid sites and compositional diversity, are typically used in separation and purification processes. ${ }^{4-5}$ In comparison to many highsilica zeolites, the synthesis of low-silica zeolites is typically mediated by alkali metal cations that act as structure directing agents (SDAs) in highly alkaline media. ${ }^{6}$ An example of such a low-silica zeolite is Linde Q with berryllophosphate-H (BPH) framework topology; a synthetic aluminosilicate with extraframework potassium $\left(\mathrm{K}^{+}\right)$cations, and a ratio of $\mathrm{Si} / \mathrm{Al} \approx 1.0$. The $\mathrm{BPH}$ framework consists of 12 membered-ring (12MR) channels along the $z$-axis perpendicularly intersected by three 8MR channels. ${ }^{7-9}$ Reported by Breck et al. in 1961, Linde Q is prepared from a $\mathrm{K}^{+}$-containing alkaline aluminosilicate precursor mixture hydrothermally treated at $50{ }^{\circ} \mathrm{C}$ for $162 \mathrm{~h}$. The synthesis and structural characterization of Linde Q, (also referred to as $\mathrm{K}-\mathrm{I}$ and zeolite Q) was investigated further in subsequent reports. ${ }^{10-15} \mathrm{It}$ was revealed that Linde Q has low thermal stability in air; undergoing structural collapse above $150{ }^{\circ} \mathrm{C} .{ }^{12,15}$ Efforts to improve the thermal stability of Linde Q have involved post-synthetic ionexchange with rare-earth metal salts, and calcination in the presence of a salt. ${ }^{16,17}$ Alternatively, synthesis procedures using OSDAs in combination with post-synthetic treatments has afforded higher silica variants (UZM-4 and PST-12, Si/Al up to 10). ${ }^{4}{ }^{4}$ ${ }^{21}$ Regarding the particle size, procedures using OSDAs and seed crystals have afforded hexagonal crystals of UZM-4 50-200 nm wide. $^{22}$

Here we report the room-temperature and OSDA-free synthesis of $\mathrm{BPH}$ (Linde Q) containing a combination of three cations $\left(\mathrm{Cs}^{+}\right.$, $\mathrm{K}^{+}$and $\mathrm{Na}^{+}$), yielding nanosheets approximately $7 \mathrm{~nm}$ thick and $90 \mathrm{~nm}$ across. The as synthesized BPH nanosheets possess high thermal (up to $500{ }^{\circ} \mathrm{C}$ ) stability due to the presence of $\mathrm{Cs}^{+}$extraframework cations and are prospective candidates for the preparation of oriented thin films and membranes for gas separation applications.

The synthesis of the BPH nanosheets involved the following steps (Scheme 1): (i) preparation of clear aqueous colloidal suspensions by rapid stirring of alkaline aluminate mixtures by combining sodium aluminate $\left(\mathrm{NaAlO}_{2}\right)$, sodium hydroxide $(\mathrm{NaOH})$, potassium hydroxide $(\mathrm{KOH})$ and cesium hydroxide $(\mathrm{CsOH})$, followed by the addition of colloidal silica $\left(\mathrm{SiO}_{2}\right)$; (ii) crystallization of BPH nanosheets from the clear colloidal suspensions under continuous stirring at room temperature between 5 to 21 days (samples labelled as BPH-5D, BPH-7D, BPH-9D, BPH14D). To explore the limits of the synthesis a sample was prepared for 21 days demonstrating negligible differences in the obtained material. For comparison, a sample was prepared hydrothermally by taking the clear precursor suspension stirred for 1 day at room temperature followed by treatment at $60{ }^{\circ} \mathrm{C}$ for 16 hours (BPH-1D-60-16). In addition, the conventional micronsized BPH was prepared as a reference. ${ }^{7}$

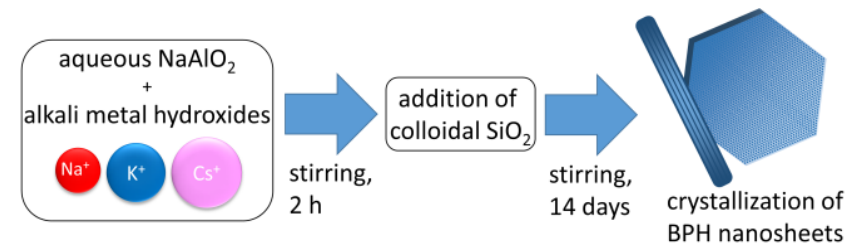

Scheme 1. Synthesis of BPH nanosheets at room temperature. 


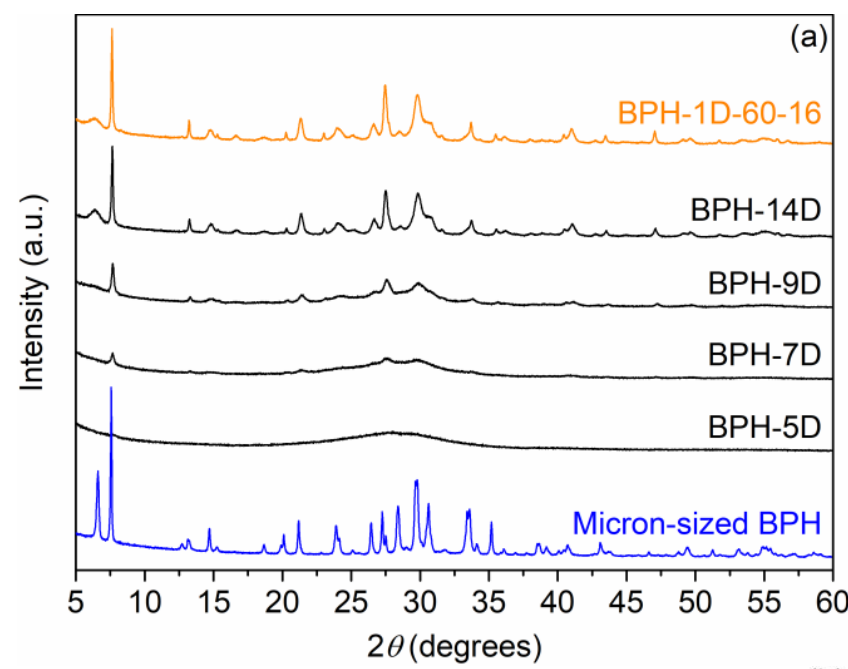

(b)

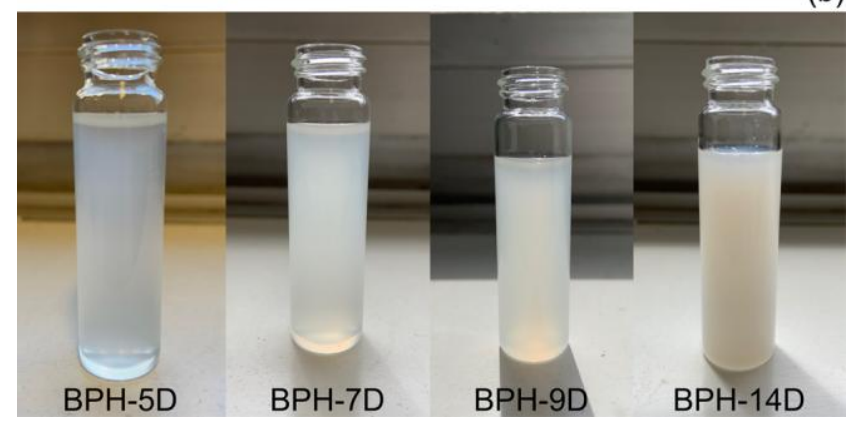

Figure 1. (a) XRD patterns of the BPH nanosheets (top to bottom) BPH-1D-60-16, BPH-14D, BPH-9D, BPH-7D, BPH-5D, and micron-sized BPH; (b) photographs of BPH-5D, 7D, 9D, and 14D samples showing the change in colloidal appearance related to the degree of crystallinity at room temperature.

XRD analysis reveals the formation of crystalline BPH after approximately 5 days at room temperature with the emergence of the (100) reflection at $\approx 7.6^{\circ} 2 \theta$ (Figures $1 \mathrm{a}, \mathrm{S} 1$ ). Coincident with the increasing intensity of the reflections is a change in the appearance of the reaction mixture from water clear to opaque (Figure $1 \mathrm{~b}$ ), related to the formation of colloidally stable zeolite particles in the suspension. Plotting the crystallinity against time reveals an approximately linear trend over the initial 14 days (Figure S2). The zeolite yield $v s$ crystallization time at roomtemperature shows two distinct regions of behavior from 5 to 9 days and 14 to 21 days, showing a significant increase in the yield of solid material between 9 and 14 days attributed to the assembly of the zeolite framework from structural building units (Figure S2).

The XRD pattern of the hydrothermally treated sample is identical to the samples synthesized at room temperature for 14 and 21 days (Figure 1A). Analysis of the XRD data of samples BPH14D, BPH-21D and BPH-1D-60-16 (Figures S3-5) was performed using the Le Bail method; the structure was fitted with the space group $P 321$ (trigonal). Comparison of the lattice parameters $(a, c)$ of the nanosheet samples with the micron-sized BPH reveals significant differences: $a$ is reduced while $c$ is increased e.g. $a=$ 13.3688, $c=13.471 \AA$ for BPH-14D vs $a=13.4909, c=13.3788$ for the micron-sized BPH (Table S1). ${ }^{14}$ Additionally, the unit cell volume of the nanosheet samples is smaller; 2085.1 for BPH-14D $v s \approx 2108.78 \AA^{3}$ for the micron-sized BPH (Table S1). ${ }^{15}$ Similar differences between the nanosheet samples (BPH-21D and BPH1D-60-16) and the micron-sized BPH were also observed. The smaller lattice parameter $a$ and the unit cell volume of the nanosheet samples is consistent with the substitution of $\mathrm{Al}^{3+}$ ions with $\mathrm{Si}^{4+}$ ions in the framework, noted by Lewis et al. for UZM4. ${ }^{4}$ This is attributed to the higher $\mathrm{Si} / \mathrm{Al}$ ratio, determined by ICP analysis, of the nanosheet samples compared to micron-sized BPH (1.3 vs 1.0, Table S2).

${ }^{29} \mathrm{Si}$ MAS NMR analysis of the nanosheet sample BPH-14D reveals a more complex spectrum compared to the micron-sized BPH which displays three sharp resonances at $-84.8,-86.0$ and $-89.9 \mathrm{ppm}$ consistent with three crystallographically distinct $\mathrm{Si}^{4+}$ sites fourfold coordinated by $\mathrm{Al}^{3+} \cdot{ }^{14-15}$ In comparison, the $\mathrm{BPH}-$ 14D nanosheets display three asymmetric resonances at -85.1 , -89.8 , and $-94.1 \mathrm{ppm}$ and several other weaker signals (Figure S6a). The shift of the three most intense resonances to lower field is attributed to the higher $\mathrm{Si} / \mathrm{Al}$ ratio (> 1.0). In comparison to the ICP results, deconvolution of the ${ }^{29} \mathrm{Si}$ spectrum of $\mathrm{BPH}-14 \mathrm{D}$ gives a $\mathrm{Si} / \mathrm{Al}$ ratio of $\approx 1.3 .{ }^{27} \mathrm{Al}$ MAS NMR analysis of the BPH-14D nanosheets revealed a single resonance at $59.4 \mathrm{ppm}$ (Figure S6b). Compared to the micron-sized BPH (61.2 ppm), the resonance in the ${ }^{27} \mathrm{Al}$ spectrum of $\mathrm{BPH}-14 \mathrm{D}$ is shifted to slightly lower field, again consistent with a higher $\mathrm{Si} / \mathrm{Al}$ ratio of $1.3 .^{14-15}$ No signal corresponding to extra-framework $\mathrm{Al}$ was observed.

TEM analysis of BPH-14D revealed the presence of welldefined and hexagonally shaped nanosheets $(90-130 \mathrm{~nm}$ wide, $7-$

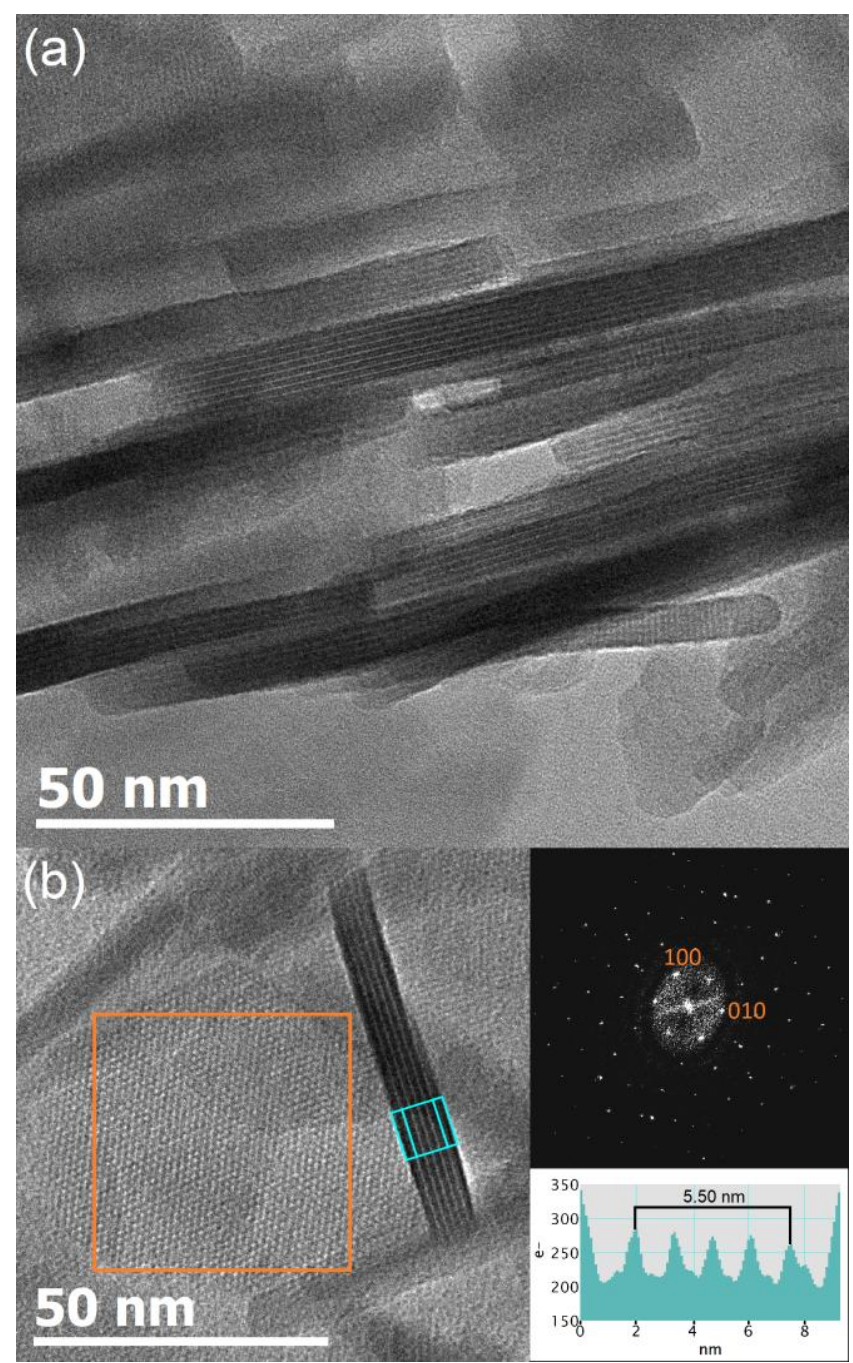

Figure 2. (a) TEM image highlighting the morphology and thickness of nanosheets in sample BPH-14D. (b) TEM analysis of the 
nanosheet sample BPH-14D including FFT (orange square) and cross-section analysis (blue rectangle).

$11 \mathrm{~nm}$ thick, Figures $2 \mathrm{a}, \mathrm{b})$. Smaller particles $(<90 \mathrm{~nm}$ at maximum width) with irregular shapes were also observed. For the hydrothermally treated sample BPH-1D-16-60 the morphology was similar to the sample BPH-14D, however, the sheets were larger (50-220 $\mathrm{nm}$ wide, 5-19 $\mathrm{nm}$ thick, Figure S7). In comparison, the micron-sized BPH was composed of plate-like crystals (Figure S8).

As mentioned in the literature, ${ }^{16}$ by exchanging the extraframework $\mathrm{K}^{+}$for $\mathrm{La}^{3+}$ it was shown that the micron-sized $\mathrm{BPH}$ could be stabilized above $150{ }^{\circ} \mathrm{C}$. The stability of the $\mathrm{BPH}$ nanosheets was investigated by in situ variable temperature XRD $\left(30-600^{\circ} \mathrm{C}\right)$. Under medium vacuum $(0.021 \mathrm{mbar})$ the nanosheets are significantly more stable compared to the micron-sized BPH, retaining $\approx 60 \%$ of their initial crystallinity at $350{ }^{\circ} \mathrm{C}$ and $\approx 44 \%$ of their initial crystallinity at $500{ }^{\circ} \mathrm{C}$ (Figures 3a, S9). In comparison, the micron-sized BPH exhibits structural collapse beginning at $150{ }^{\circ} \mathrm{C}$ and almost complete amorphization at $350{ }^{\circ} \mathrm{C}$ under medium vacuum (Figure $3 b, S 10$ ).

With the improved thermal stability of the nanosheets under medium vacuum their adsorption properties were evaluated. TGA of BPH-14D under low vacuum (1.4 mbar) reveals weight loss below $100{ }^{\circ} \mathrm{C}$ attributed to the release of surface water (Figure S11). Further weight loss is observed at $150{ }^{\circ} \mathrm{C}$ with almost
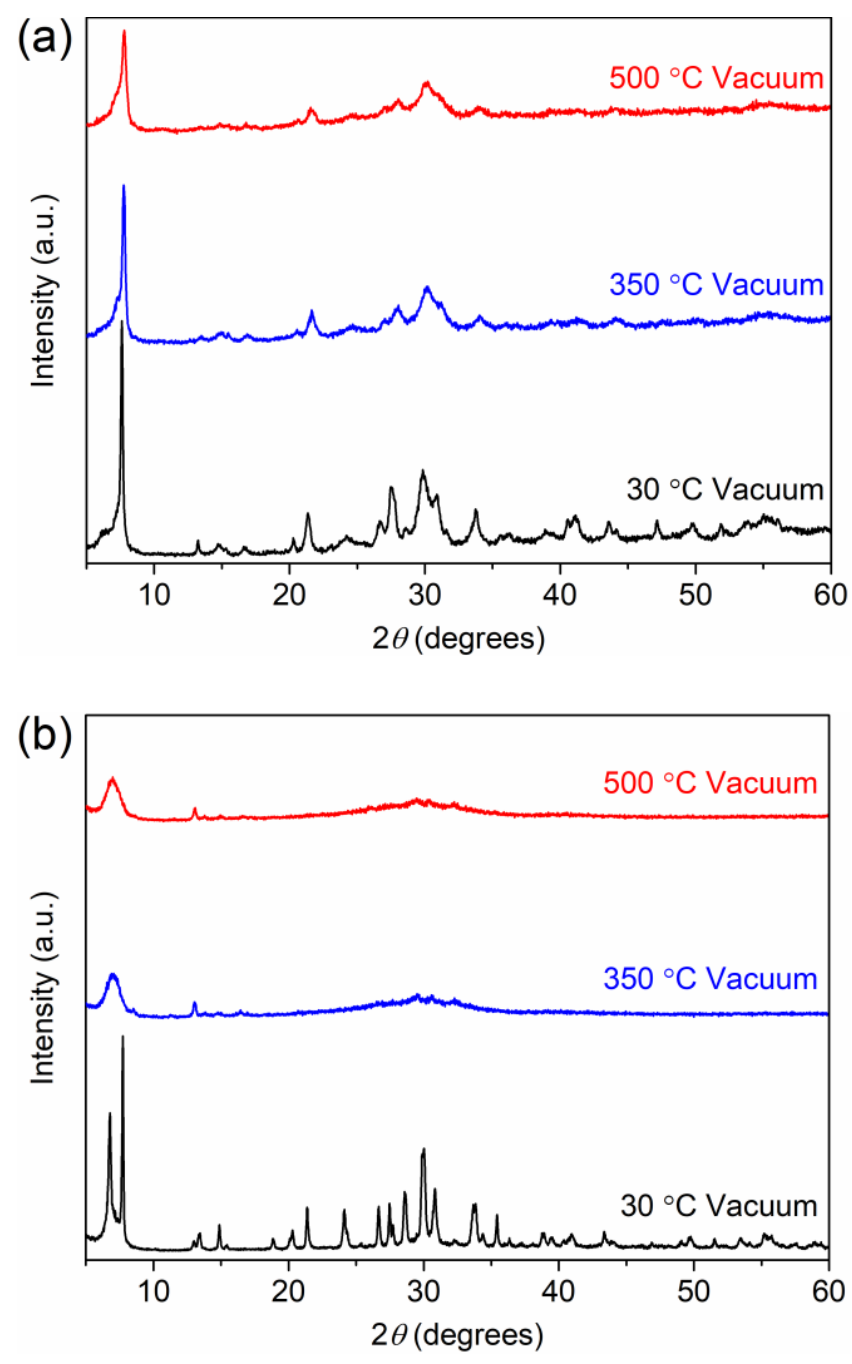

Figure 3. XRD patterns recorded at $30{ }^{\circ} \mathrm{C}$ (black), $350{ }^{\circ} \mathrm{C}$ (blue) and $500{ }^{\circ} \mathrm{C}$ (red) under medium vacuum (0.021 mbar) of (a) BPH14D nanosheets, and (b) micron-sized $\mathrm{BPH}$.
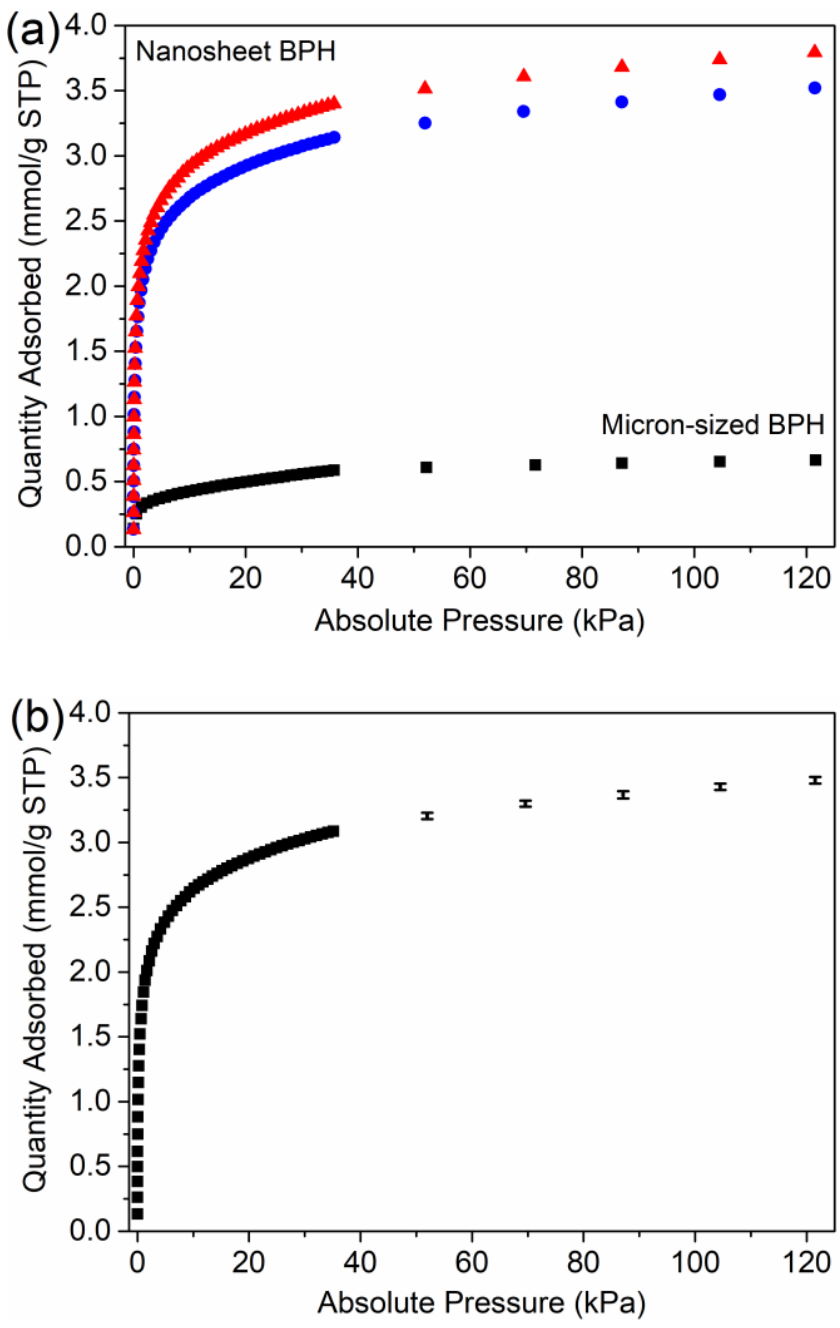

Figure 4. (a) $\mathrm{CO}_{2}$ adsorption isotherms $\left(0{ }^{\circ} \mathrm{C}\right)$ of the nanosheet samples BPH-1D-60-16 (red triangles), BPH-14D (blue circles), and micron-sized BPH (black squares). (b) Average $\mathrm{CO}_{2}$ adsorption isotherm of three consecutive measurements of the nanosheet sample BPH-14D, the last five data points present the standard deviation.

complete dehydration occurring by $200{ }^{\circ} \mathrm{C}$. Similarly, the micronsized BPH shows almost complete dehydration by $200{ }^{\circ} \mathrm{C}$ but with weight loss occurring at $\approx 100$ and $150{ }^{\circ} \mathrm{C}$. The different behavior of the two samples is attributed to the different surface area allowing for more water molecules to be bound to the external surface of the nanosheets and a more rapid diffusion of water through the zeolite.

Prior to adsorption analysis the samples were pre-treated at 350 ${ }^{\circ} \mathrm{C}$ under high vacuum $(2.67 \mu$ bar $) . \mathrm{N}_{2}$ adsorption analysis shows that the BPH nanosheets exhibit a mixture of type I and IV isotherms with a type $\mathrm{H} 1$ hysteresis attributed to interparticle mesopores (Figure S12, Table S3). In comparison, the micronsized BPH possesses a negligible BET specific surface area and low micropore volume. Similarly, the $\mathrm{CO}_{2}$ adsorption capacity of the $\mathrm{BPH}$ nanosheets is significantly greater, up to $3.78 \mathrm{mmol} / \mathrm{g}$, as compared to the micron-sized BPH (Figure 4a) which undergoes structural collapse (Figure S13); these results clearly demonstrate the superior thermal stability of the nanosheets under vacuum. The $\mathrm{CO}_{2}$ adsorption capacity of the $\mathrm{BPH}$ nanosheets is compara- 
ble to commercial $\mathrm{Na}^{+} / \mathrm{K}^{+}$-LTA and Cs-CHA at $0{ }^{\circ} \mathrm{C},{ }^{23-25}$ but less than $\mathrm{Na}^{+}$-LTA $(4 \mathrm{~A})$ at $0{ }^{\circ} \mathrm{C}$, and FAU (NaY and $\mathrm{NaX}$ ) zeolites at $25^{\circ} \mathrm{C} .{ }^{26}$ The nanosheets demonstrate consistent adsorption behavior over three consecutive measurements with less than $1 \%$ standard deviation (Figure 4b). The adsorption behavior of the nanosheets was investigated further by performing multiple TG cycles of heating $\left(350{ }^{\circ} \mathrm{C}\right)$ under low vacuum $(1.4 \mathrm{mbar})$ and flowing $\mathrm{CO}_{2}$ at $25{ }^{\circ} \mathrm{C}$ (Figure 5a). The nanosheets display an initial decrease in $\mathrm{CO}_{2}$ capacity attributed to the formation of carbonate species (vide infra) followed by stable behavior.

To determine the cause of the greater stability of the BPH nanosheets, Cs ion-exchange of the micron-sized $\mathrm{BPH}$ was performed and the product analyzed by $\mathrm{CO}_{2}$ adsorption and XRD (Supporting Information). The Cs-micron-sized BPH exhibited a similar $\mathrm{CO}_{2}$ adsorption capacity compared to the $\mathrm{BPH}$ nanosheets prepared at room temperature (Figure S14). XRD revealed the Csmicron-sized $\mathrm{BPH}$ after $\mathrm{CO}_{2}$ adsorption had lost a greater degree of crystallinity compared to the BPH nanosheets (Figure S15). These results demonstrate that the greater stability of the $\mathrm{BPH}$ nanosheets compared to the conventional micron-sized $\mathrm{BPH}$ is due to the presence of the extra-framework $\mathrm{Cs}^{+}$.

In situ FTIR spectroscopy of the $\mathrm{BPH}$ nanosheets with $\mathrm{CO}_{2}$ revealed the formation of chemisorbed species between 1800 and $1200 \mathrm{~cm}^{-1}$ (Figure 5b). ${ }^{27}$ The bands at 1416 and $1441 \mathrm{~cm}^{-1}$ are attributed to carboxylate and free carbonate species; rapidly reaching maximum absorbance before equilibrium. The most prominent bands have maxima at 1363 and $1668 \mathrm{~cm}^{-1}$, attributed to bridged bidentate carbonates. The band at $1363 \mathrm{~cm}^{-1}$ was accompanied by shoulders at 1339 and $1374 \mathrm{~cm}^{-1}$ while the band at $1668 \mathrm{~cm}^{-1}$ exhibited shoulders at $1639,1682 \mathrm{~cm}^{-1}$, and a weaker
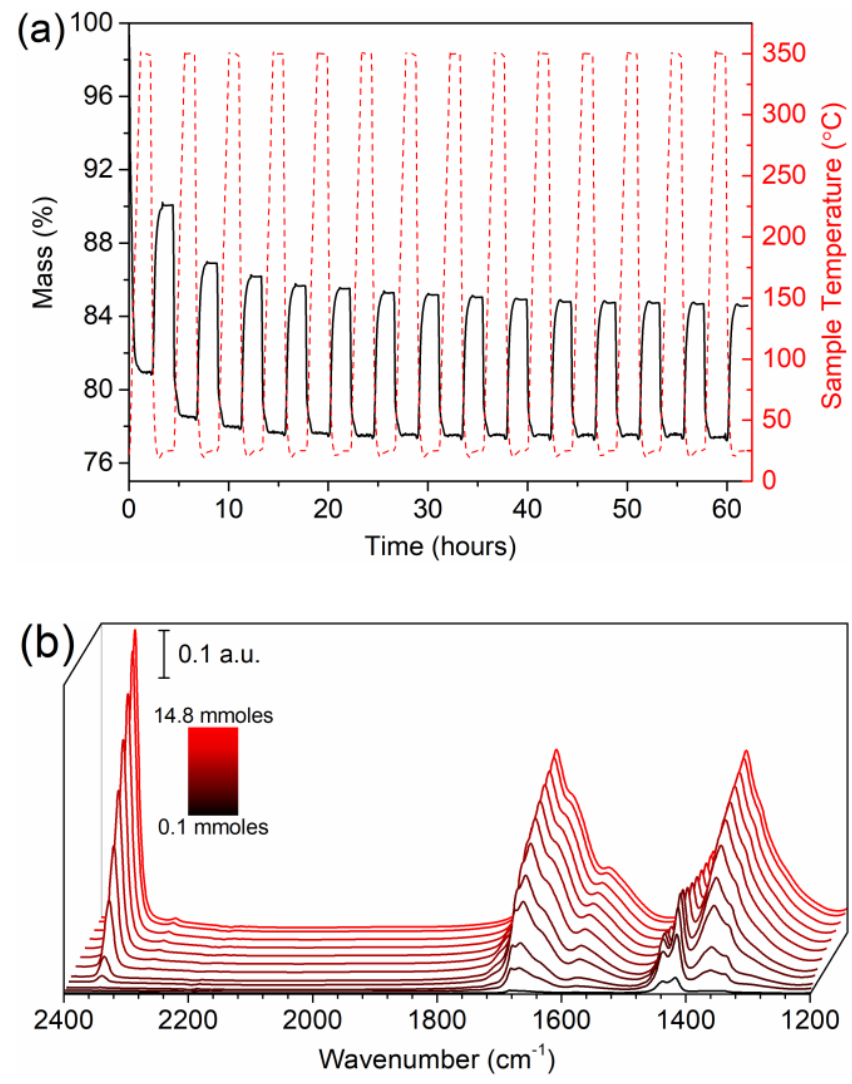

Figure 5. (a) TG cycles of BPH-14D treated at $350{ }^{\circ} \mathrm{C}$ under low vacuum (1.4 mbar) followed by flowing $\mathrm{CO}_{2}(40 \mathrm{~mL} / \mathrm{min})$ at 25 ${ }^{\circ} \mathrm{C}$, mass: black solid line, sample temperature: red dashed line. (b) In situ FTIR spectra of BPH-14D under increasing $\mathrm{CO}_{2}$ atmosphere, pre-treated at $350{ }^{\circ} \mathrm{C}$ under high vacuum $\left(10^{-3} \mu\right.$ bar $)$.

shoulder at $1716 \mathrm{~cm}^{-1}$. A broad and less intense band was observed at $1585 \mathrm{~cm}^{-1}$ indicative of carboxylate species. Physisorbed $\mathrm{CO}_{2}$, including ${ }^{13} \mathrm{CO}_{2}$, was identified by the $v_{3}$ asymmetric stretches at 2346 and $2280 \mathrm{~cm}^{-1}$. Removal of the $\mathrm{CO}_{2}$ under high vacuum followed by a second activation treatment revealed the retention of free $\left(1435,1421 \mathrm{~cm}^{-1}\right)$ and bridged bidentate (1663 $\mathrm{cm}^{-1}$ ) carbonates which may have implications for selective separation of $\mathrm{CO}_{2}$ due to carbonate-promoted cation displacement (Figure S14). ${ }^{28}$

In conclusion, we have achieved the room-temperature OSDAfree synthesis of BPH nanosheets possessing high thermal stability under vacuum and $\mathrm{CO}_{2}$ adsorption capacity. Nanosheets with dimensions approximately $7 \mathrm{~nm}$ thick and $90 \mathrm{~nm}$ wide possess a $\mathrm{Si} / \mathrm{Al}$ ratio of 1.3 and superior thermal stability up to $500{ }^{\circ} \mathrm{C}$ under vacuum compared to conventional micron-sized $\mathrm{BPH}$ (Linde Q) due to the presence of $\mathrm{Cs}^{+}$extra-framework cations. The nanosheets demonstrate considerable $\mathrm{CO}_{2}$ adsorption capacity, comparable to commercial $\mathrm{Na}^{+} / \mathrm{K}^{+}$-LTA and Cs-CHA zeolites, ${ }^{23-25}$ while investigation of the thermal behavior under different degrees of vacuum (low, medium, high) indicates that the application of a higher vacuum results in a greater retention of the initial crystallinity and sorption capacity of the nanosheets. The nanosheets are colloidally stable and are ideal candidates for the preparation of oriented thin films and membranes for gas separation applications.

\section{ASSOCIATED CONTENT}

\section{Supporting Information}

Contains information pertaining to materials, equipment and experimental procedures, Le Bail refinement data, ICP results, XRD and in situ variable temperature XRD under vacuum, TEM, SEM, ${ }^{29} \mathrm{Si}$ and ${ }^{27} \mathrm{Al}$ MAS NMR, TGA, $\mathrm{N}_{2}$ and Ar adsorption data. The Supporting Information is available free of charge on the ACS Publications website at DOI:

\section{AUTHOR INFORMATION}

\section{Corresponding Author}

*E-mail: mintova@ensicaen.fr

Notes

The authors declare no competing financial interests.

\section{ACKNOWLEDGMENT}

Financial support from TOTAL and Industrial Chair ANR-TOTAL "Nanoclean Energy" is acknowledged as well as from the Normandy Region through the RIN Recherche Program.

\section{REFERENCES}

(1) Vermeiren, W.; Gilson, J.-P., Impact of Zeolites on the Petroleum and Petrochemical Industry. Top. Catal. 2009, 52 (9), 1131-1161.

(2) Mintova, S.; Gilson, J.-P.; Valtchev, V., Advances in nanosized zeolites. Nanoscale 2013, 5 (15), 6693-6703.

(3) Li, J.; Corma, A.; Yu, J., Synthesis of new zeolite structures. Chem. Soc. Rev. 2015, 44 (20), 7112-7127.

(4) Blackwell, C. S.; Broach, R. W.; Gatter, M. G.; Holmgren, J. S.; Jan, D. Y.; Lewis, G. J.; Mezza, B. J.; Mezza, T. M.; Miller, M. A.; Moscoso, J. G., Open- Framework Materials Synthesized in the $\mathrm{TMA}^{+} / \mathrm{TEA}^{+}$Mixed- Template System: The New Low Si/Al Ratio Zeolites UZM- 4 and UZM- 5. Angew. Chem. Int. Ed. 2003, 42 (15), 1737-1740. 
(5) Barrett, P.; Huo, Q.; Stephenson, N., Recent advances in low silica zeolite synthesis. In Stud. Surf. Sci. Catal., Elsevier: 2007; Vol. 170, pp 250-257.

(6) Flanigen, E. M., A Review and New Perspectives in Zeolite Crystallization. In Molecular Sieves, Meier, M. W.; Uytterhoeven, J. B. Eds. ACS Publications: 1973; Vol. 121, pp 119-139.

(7) Breck, D. W.; Acara, N. A. Crystalline Zeolite Q. US2991151A, 1961.

(8) Harvey, G., The synthesis and structure of beryllophosphate-H - A new open-framework zeolite. Z. Kristallogr. 1988, 182 (1-4), 123-124.

(9) Harvey, G.; Baerlocher, C.; Wroblewski, T., Structure solution and Rietveld refinement of beryllophosphate-H zeolite. Z. Kristallogr. - Cryst. Mater. 1992, 201 (1-4), 113-124.

(10) Zhdanov, S. P.; Ovsepyan, M., Some synthetic potash zeolites and their properties. Dokl. Akad. Nauk 1964, 157 (4), 913-916.

(11) Zhdanov, S. P.; Buntar-Samulevich, N.; Ovsepyan, M., Synthetic chabasites and their adsorptive properties. Dokl. Akad. Nauk 1965, 161 (2), 384-387.

(12) Barrer, R.; Cole, J.; Sticher, H., Chemistry of soil minerals. Part V. Low temperature hydrothermal transformations of kaolinite. J. Soc. Chem. A 1968, 2475-2485.

(13) Bosmans, H. J.; Tambuyze, E.; Paenhuys, J.; Ylen, L.; Vancluys, J., Zeolite Formation in the System $\mathrm{K}_{2} \mathrm{O}-\mathrm{Na}_{2} \mathrm{O}-\mathrm{Al}_{2} \mathrm{O}_{3}-\mathrm{SiO}_{2}-\mathrm{H}_{2} \mathrm{O}$. In Molecular Sieves, Meier, M. W.; Uytterhoeven, J. B., Eds. ACS Publications: 1973; Vol. 121, pp 179-188.

(14) Andries, K.; Bosmans, H.; Grobet, P., The crystal structure of zeolite Linde Q: A proposal based on powder X-ray diffraction and ${ }^{27} \mathrm{~A}$ and ${ }^{29} \mathrm{Si}$ MAS nmr spectroscopy. Zeolites 1991, 11 (2), 124-131.

(15) Andries, K.; De Wit, B.; Grobet, P.; Bosmans, H., The synthesis and properties of synthetic zeolite Linde Q. Zeolites 1991, 11 (2), 116123.

(16) Vaughan, D. E. W. ECR-33: a stabilized rare-earth exchanged Q type zeolite. US5382420A, 1995.

(17) Huo, Q.; Stephenson, N. A. Stabilization of molecular sieves by salt addition. US6632767B2, 2003.

(18) Lewis, G. J.; Moscoso, J. G.; Miller, M. A.; Wilson, B. A. Crystalline aluminosilicate zeolitic composition: UZM-4. US6419895B1, 2002.

(19) Wilson, B. A.; Lewis, G. J.; Jan, D.-Y.; Wilson, S. T.; Patton, R. L. Crystalline aluminosilicate zeolitic composition: UZM-4M. US6776975B2, 2004

(20) Miller, M. A.; Moscoso, J. G.; Koster, S. C.; Gatter, M. G.; Lewis, G. J., Synthesis and characterization of the 12-ring zeolites UZM-4 (BPH) and UZM-22 (MEI) via the charge density mismatch approach in the Choline- $\mathrm{Li}_{2} \mathrm{O}-\mathrm{SrO}-\mathrm{Al}_{2} \mathrm{O}_{3}-\mathrm{SiO}_{2}$ system. In Stud. Surf. Sci. Catal., Elsevier: 2007; Vol. 170, pp 347-354

(21) Park, M. B.; Ahn, S. H.; Ahn, N. H.; Hong, S. B., Charge density mismatch synthesis of MEI-and BPH-type zeolites in the TEA ${ }^{+}-\mathrm{TMA}^{+}$ $\mathrm{Li}^{+}-\mathrm{Sr}^{2+}$ mixed-structure-directing agent system. Chem. Commun. 2015 , 51 (17), 3671-3673

(22) Moteki, T.; Okubo, T., From Charge Density Mismatch to a Simplified, More Efficient Seed-Assisted Synthesis of UZM-4. Chem. Mater. 2013, 25 (13), 2603-2609.

(23) Rzepka, P.; Wardecki, D.; Smeets, S.; Müller, M.; Gies, H.; Zou, $\mathrm{X}$.; Hedin, N., $\mathrm{CO}_{2}$-Induced Displacement of $\mathrm{Na}^{+}$and $\mathrm{K}^{+}$in Zeolite $|\mathrm{NaK}|$ A. J. Phys. Chem. C 2018, 122 (30), 17211-17220.

(24) Shang, J.; Li, G.; Singh, R.; Xiao, P.; Liu, J. Z.; Webley, P. A., Determination of composition range for "molecular trapdoor" effect in chabazite zeolite. J. Phys. Chem. C 2013, 117 (24), 12841-12847.

(25) Debost, M.; Klar, P. B.; Barrier, N.; Clatworthy, E. B.; Grand, J.; Lainé, F.; Brazda, P.; Palatinus, L.; Nesterenko, N.; Boullay, P., Synthesis of discrete CHA zeolite nanocrystals without organic templates for selective $\mathrm{CO}_{2}$ capture. Angew. Chem. Int. Ed. 2020, 132.

(26) Walton, K. S.; Abney, M. B.; LeVan, M. D., CO2 adsorption in Y and $\mathrm{X}$ zeolites modified by alkali metal cation exchange. Microporous Mesoporous Mater. 2006, 91 (1-3), 78-84.

(27) Stevens Jr, R. W.; Siriwardane, R. V.; Logan, J., In situ Fourier transform infrared (FTIR) investigation of $\mathrm{CO}_{2}$ adsorption onto zeolite materials. Energy Fuels 2008, 22 (5), 3070-3079.

(28) Bryukhanov, I. A.; Rybakov, A. A.; Larin, A. V., CarbonatePromoted Drift of Alkali Cations in Small Pore Zeolites: Ab Initio Molecular Dynamics Study of $\mathrm{CO} 2$ in NaKA Zeolite. The Journal of Physical Chemistry Letters 2019, 10 (9), 2191-2195. 
Insert Table of Contents artwork here

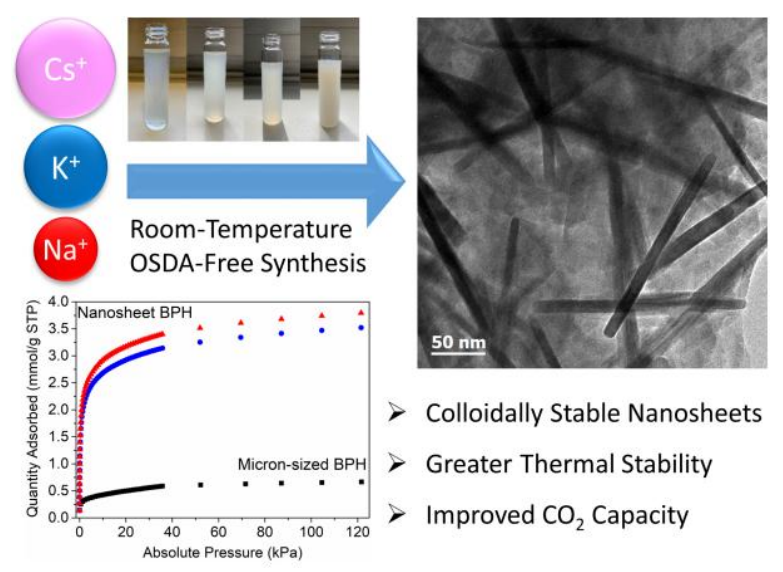

